\title{
Hydrogen Sulfide: A Reagent for pH-Driven Bio-Inspired 1,2-Diol Mono-Deoxygenation and Carbonyl Reduction in Water
}

\author{
Sebastián Barata-Vallejo, ${ }^{\dagger, \ddagger}$ Carla Ferreri, ${ }^{\dagger}$ Bernard T. Golding, ${ }^{\S}$ and Chryssostomos Chatgilialoglu ${ }^{\dagger, *}$ \\ ${ }^{\dagger}$ ISOF, Consiglio Nazionale delle Ricerche, Via P. Gobetti 101, 40129 Bologna, Italy. ${ }^{\circledR}$ School of Natural \& Environmental \\ Sciences, Newcastle University, Newcastle upon Tyne NE1 7RU, UK.
}

Supporting Information Placeholder

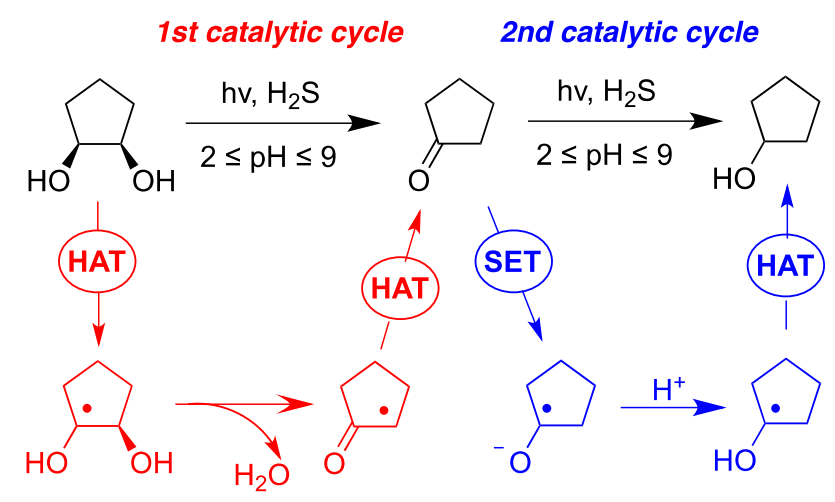

ABSTRACT: Hydrogen sulfide $\left(\mathrm{H}_{2} \mathrm{~S}\right)$ was evaluated for its peculiar sulfur radical species generated at different $\mathrm{pHs}$, and was used under photolytical conditons in aqueous medium for the reduction of 1,2-diols to alcohols. The conversion steps of 1,2-cyclopentanediol to cyclopentanol via cyclopentanone was analyzed and it was proven that the reaction proceeds via a dual catalytic radical mechanism. This approach was successfully adapted to the reduction of a variety of carbonyl compounds using $\mathrm{H}_{2} \mathrm{~S}$ at $\mathrm{pH} 9$ in water. This work opens up the field of environmental friendly synthetic processes using the $\mathrm{pH}$-driven modulation of reactivity of this simple reagent in water.

The selective deoxygenation of a 1,2-diol to an alcohol is a difficult chemical conversion that has a myriad of potential synthetic applications and is fundamental to the origin of life. In principle, this conversion can be accomplished by dehydration of a 1,2-diol to an aldehyde or ketone followed by a reduction. The foremost known pathways for the reduction or dehydration of 1,2-diols proceed via intermediate radicals. The BartonMcCombie reaction is, for example, a multi-step approach that is applicable to sugar substrates and involves protection and derivatization to an intermediate that undergoes a radical-mediated deoxygenation reaction. ${ }^{1,2}$

The mono-deoxygenation of a 1,2-diol is performed in nature by ribonucleotide reductases that employ thiyl radical based chemistry (Fig. 1). The ribose unit of ribonucleotide diphosphates is converted into 2-deoxyribose units required as building blocks for the de novo synthesis of DNA. ${ }^{3,4}$ In this mechanism, ${ }^{5,6}$ one of the cysteine residues at the active site generates a thiyl radical $\mathrm{CyS}^{*}$ which effects $\mathrm{H}$-abstraction from $\mathrm{C}-3$. There follows elimination of the 2-OH group with translocation of the radical center to C-2, quenching of the newly formed C-2 radical and reduction of the C-3 carbonyl group. Essentially, a (3',2')-spin center shift occurs, eliciting a $\beta-\mathrm{C}-\mathrm{O}$ scission and elimination of water. ${ }^{7}$ A pair of cysteine residues provide the electrons via a disulfide radical anion to reduce the intermediate ketone to an alcohol.

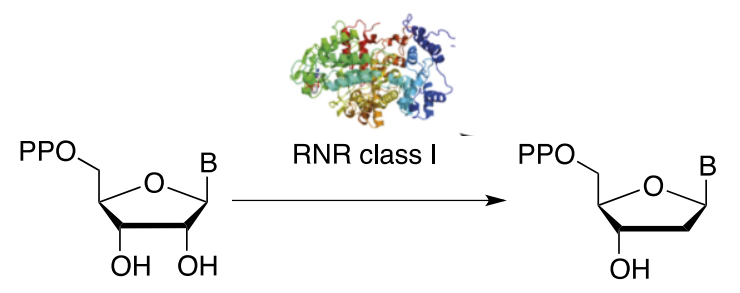

Figure 1. Transformation of ribonucleotides to 2'-deoxy-ribonucleotides.

The dehydration of simple 1,2-diols initiated by $\mathrm{HO}^{*}$ radicals with formation of the corresponding aldehyde or ketone has been extensively studied, principally as a model system for carbohydrate substrates, ${ }^{8}$ and in connection with the mechanism of diol dehydratase. ${ }^{9,10}$ The 1,2-dihydroxyalkyl radicals that are intermediates in this reaction readily undergo either acid- or basecatalyzed elimination of water to afford a carbon-centered radical stabilized by an adjacent carbonyl group. ${ }^{11}$ The intermediate carbonyl compound formation has a very large industrial utilization 
for natural products and polyols conversions and efforts are carried out in this field toward environmentally friendly approaches in water. ${ }^{12,13}$

The enzymatic mechanisms operating in Fig. 1 can be taken as inspiration for using sulfur radical chemistry in the 1,2-diol transformation to mono-alcohols and the reduction of carbonyl compounds. Indeed, bio-inspired chemical conversions are quite interesting since they open up perspectives for new catalytic processes as well as for green methodologies. ${ }^{14}$ The simplest thiol $\mathrm{H}_{2} \mathrm{~S}$ in the last decade has attracted increasing interest in a multidisciplinary context from chemistry to biology. ${ }^{15,16}$ Research has highlighted the strong versatility of this molecule due to a variety of oxidation states ${ }^{17,18}$ and the peculiar reactivity of its sulfhydryl and disulfide radical species driven by different $\mathrm{pHs}$ in aqueous systems. Some of us previously investigated the $\mathrm{pH}$-sensitive biomimetic cis-trans isomerization process involving unsaturated fatty acids in liposomes with sulfhydryl radical (HS*) derived from protein modifications or $\mathrm{H}_{2} \mathrm{~S} .{ }^{19,20}$ This simple molecule, present among the other gases in primordial atmosphere, ${ }^{21}$ attracts interest in prebiotic reactions in connection with the origin of life. ${ }^{22,23}$

Here, we report the direct conversion of 1,2-cyclopentane diol to cyclopentanol, starting from the photolysis of $\mathrm{H}_{2} \mathrm{~S}$ at different $\mathrm{pH}$ values in aqueous medium with a complete mechanistic picture. In particular, based on the properties of the $\mathrm{HS}^{*}$ radical and inspired by the biological mechanism of ribonucleotide reductases, we developed a dual catalytic system capable of unprecedented organic transformations using $\mathrm{H}_{2} \mathrm{~S}$ radical chemistry.

Thus, $\mathrm{Na}_{2} \mathrm{~S}$ was used as source of $\mathrm{H}_{2} \mathrm{~S}$ in aqueous solution for the reduction of cis-1,2-cyclopentanediol (1) under photolytical conditions in the absence of oxygen. Photolysis (low-pressure $\mathrm{Hg}$ lamp, $5.5 \mathrm{~W})$ of $\mathrm{N}_{2}$-saturated aqueous solutions of $1(8.3 \mathrm{mM})$ containing $\mathrm{Na}_{2} \mathrm{~S} .9 \mathrm{H}_{2} \mathrm{O}(16.6 \mathrm{mM})$ was monitored for up to 60 min and at various $\mathrm{pH}$ values (2, 4.5, 7 and 9). In all experiments, cyclopentanone (2) and cyclopentanol (3) were the only products. The extent of formation of these products under various conditions is summarized in Table 1 (see also Fig. S2-S5). Fig. 2a shows the irradiation time profile of the disappearance of $1(\square, \mathbf{\square})$ and the formation of $2(\bigcirc, \bullet)$ and $3(\triangle, \mathbf{\Delta})$ at $\mathrm{pH} 4.5$ (dashed lines) and 7 (full lines), respectively. The percentage of starting material conversion was similar, i.e., after $60 \mathrm{~min}$, a $45 \%$ conversion was obtained at $\mathrm{pH} 4.5(\square)$ and $52 \%(\square)$ at $\mathrm{pH} 7$, whereas in the product distribution cyclopentanone predominated at $\mathrm{pH} 4.5(\bigcirc)$ and cyclopentanol at $\mathrm{pH} 7(\boldsymbol{\Delta})$. The ratio of the two products was strongly influenced by the $\mathrm{pH}$ conditions and also by the reaction time, indicating the intermediacy of 2 in the formation of product 3 .

Trans-1,2-cyclopentanediol behaves exactly like the cis-isomer, giving the same conversion and the same trend in the product formation for 2 and 3 (see Fig. S6). Further support for the intermediate reduction step $2 \rightarrow 3$ was obtained by observing the direct reduction of cyclopentanone (2) under identical experimental conditions. Fig. $2 \mathrm{~b}$ shows the irradiation time profile for the formation of 3 at various $\mathrm{pHs}$ (see Fig. S7). Interestingly, reduction efficiency increases with $\mathrm{pH}$, becoming very effective at $\mathrm{pH} 9$.
Table 1. Photolysis (low pressure $\mathrm{Hg}$ lamp, $5.5 \mathrm{~W}$ ) of $\mathrm{N}_{2}$-saturated aqueous solutions of cis1,2-cyclopentanediol (1,8.3 mM) containing $\mathrm{Na}_{2} \mathrm{~S} .9 \mathrm{H}_{2} \mathrm{O}(16.6 \mathrm{mM})$ with formation of cyclopentanone (2) and cyclopentanol (3) at different irradiation times and $\mathrm{pH}$. Reaction temperature was constant at $42 \pm 1{ }^{\circ} \mathrm{C}$.

\begin{tabular}{lllll}
$\mathrm{pH}$ & time, min & $1, \mathrm{mM}$ & $2, \mathrm{mM}$ & $3, \mathrm{mM}$ \\
\hline 2 & 20 & 6.7 & 1.5 & 0.1 \\
& 40 & 5.3 & 2.7 & 0.3 \\
& 60 & 4.7 & 3.1 & 0.5 \\
4.5 & 20 & 6.5 & 1.3 & 0.5 \\
& 40 & 5.2 & 2.1 & 1.0 \\
7 & 60 & 4.6 & 2.4 & 1.3 \\
& 20 & 5.9 & 0.5 & 1.9 \\
& 40 & 4.6 & 0.9 & 2.8 \\
9 & 60 & 3.9 & 1.2 & 3.2 \\
& 30 & 7.8 & $b$ & 0.5 \\
& 40 & 7.3 & $b$ & 1.0 \\
& 60 & 6.2 & $b$ & 2.1
\end{tabular}

${ }^{a} \mathrm{pH}=7.5$, after 60 minutes irradiation. ${ }^{b}$ Undetectable

a

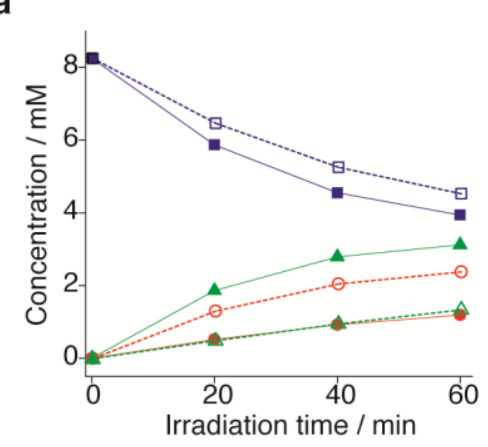

b

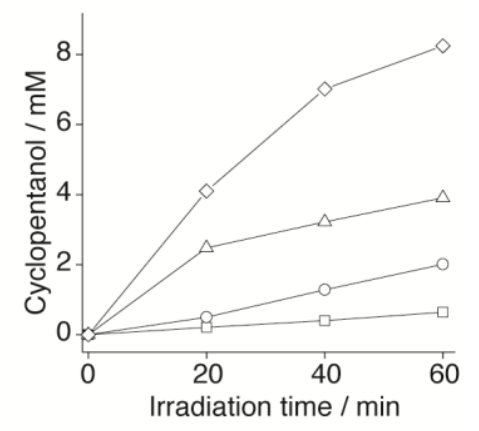

Figure 2. (a) Monodeoxygenation of cis-1,2-cyclopentanediol; concentration of $1(\square, \boldsymbol{\square}), 2(\bigcirc, \bullet)$ and $3(\triangle, \Delta)$ vs irradiation time at $\mathrm{pH} 4.5$ (dashed lines) and $\mathrm{pH} 7$ (full lines) for the photolysis of $\mathrm{N}_{2}$ saturated cis-1,2-cyclopentanediol (1) aqueous solutions (8.3 mM) containing $\mathrm{Na}_{2} \mathrm{~S} .9 \mathrm{H}_{2} \mathrm{O}(16.6 \mathrm{mM})$. (b) Formation of 3 vs irradiation time for the photolysis of $\mathrm{N}_{2}$-saturated cyclopentanone (2) aqueous solutions $(8.3 \mathrm{mM})$ containing $\mathrm{Na}_{2} \mathrm{~S} .9 \mathrm{H}_{2} \mathrm{O}(16.6 \mathrm{mM})$, different irradiation times and $\mathrm{pH}$ values: $\square, \mathrm{pH} 2 ; \bigcirc, \mathrm{pH} 4.5 ; \triangle \mathrm{pH} 7 ; \diamond$, pH 9. 
a

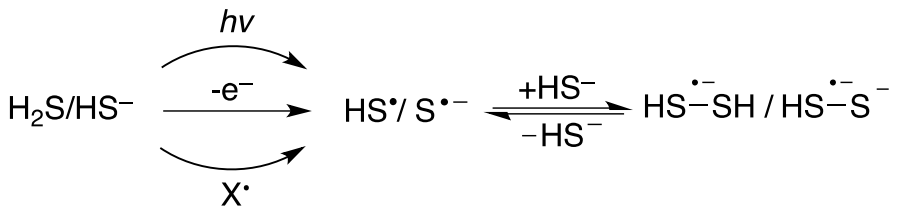

b

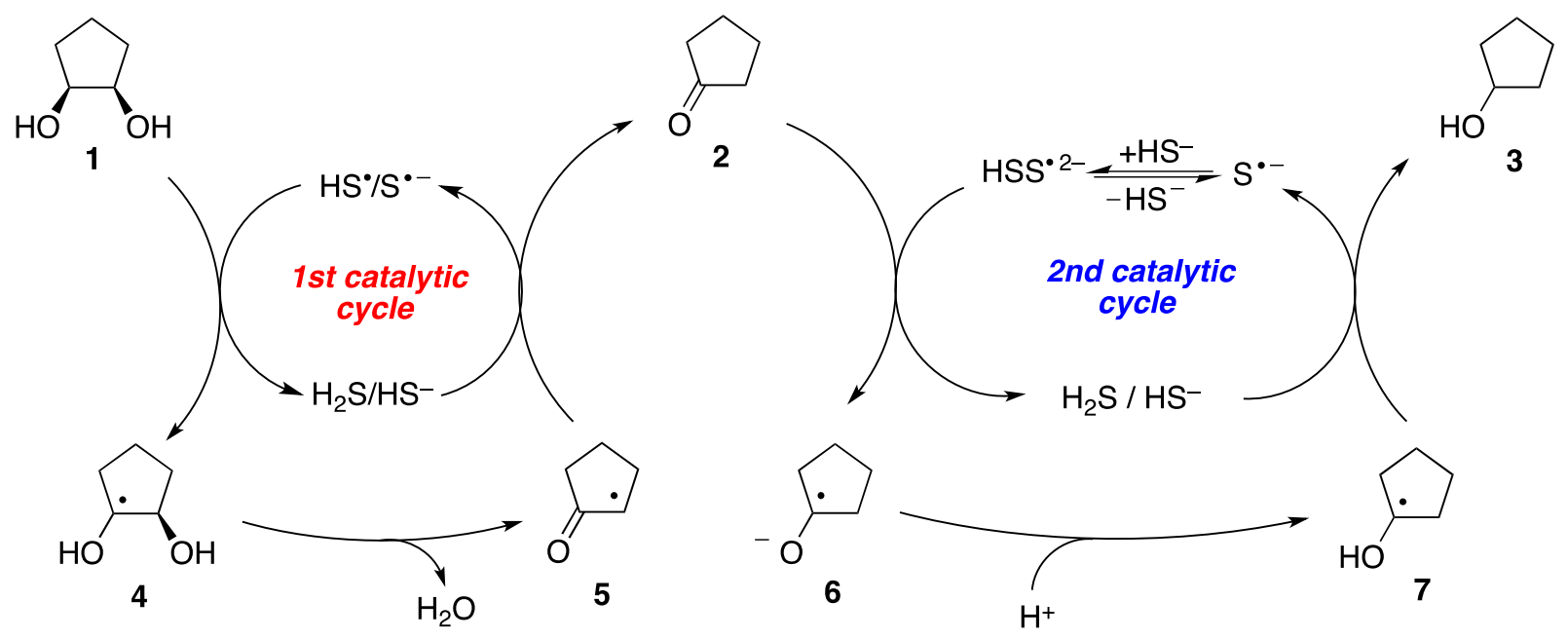

Figure 3. (a) Hydrogen sulfide $\left(\mathrm{H}_{2} \mathrm{~S} / \mathrm{HS}^{-}\right)$affords the sulfhydryl radical ( $\left.\mathrm{HS}{ }^{*} / \mathrm{S}^{-}\right)$that adds reversibly to the parent compound to form the dimeric radical species. (b) Dual catalytic system for the deoxygenation of cis-1,2-cyclopentanediol (1) to cyclopentanol (3) via cyclopentanone (2).

To evaluate the versatile behavior of $\mathrm{H}_{2} \mathrm{~S}$, its properties must be considered: its weak acidity $\left(\mathrm{p} K_{\mathrm{a}} 6.98\right.$ at $25^{\circ} \mathrm{C}, 6.76$ at 37 ${ }^{\circ} \mathrm{C}^{24}$ ); one electron reduction and hydrogen abstraction from both $\mathrm{H}_{2} \mathrm{~S}$ and $\mathrm{HS}^{-}$under photolytic conditions (Fig. 3a). The sulfhydryl radical $\left(\mathrm{HS}^{*} / \mathrm{S}^{-}{ }^{-}\right)$has a $\mathrm{p} K_{\mathrm{a}}$ value $(\sim 4)$ three units lower than that of $\mathrm{H}_{2} \mathrm{~S}^{20,25}$ The HS ${ }^{*}$ radical adds reversibly to HS $^{-}$to form the dimer radical HSSH ${ }^{--}\left(\mathrm{pK} \mathrm{a}_{\mathrm{a}}\right.$ unknown). The $\mathrm{S}^{-}$ adds reversibly to $\mathrm{HS}^{-}$to give $\mathrm{HSS}^{\bullet-2}$, with forward and reverse rate constants of $4.0 \times 10^{9} \mathrm{M}^{-1} \mathrm{~s}^{-1}$ and $5.1 \times 10^{5} \mathrm{~s}^{-1}$, respectively, with the equilibrium constant $K_{\text {eq }}$ being $8,000 \mathrm{M}^{-1} .{ }^{25}$ The bond dissociation enthalpy of $\mathrm{H}_{2} \mathrm{~S}, \quad \mathrm{DH}_{298}(\mathrm{HS}-\mathrm{H})$ is $91.2 \pm 0.1$ $\mathrm{kcal} / \mathrm{mol}$, which is $3.8 \mathrm{kcal} / \mathrm{mol}$ stronger than methanethiol $\left[\mathrm{DH}_{298}\left(\mathrm{CH}_{3} \mathrm{~S}-\mathrm{H}\right)=87.4 \pm 0.5\right] . \mathrm{H}_{2} \mathrm{~S}$ reactivity is therefore analogous to that of thiols with respect to $\mathrm{H}$-atom donation and $\mathrm{H}$ atom abstraction by the $\mathrm{HS}^{\circ}$ radical (Fig. 3a). ${ }^{26}$ The reduction potential of the dimeric radical, $E\left(\mathrm{HSS}^{-2-}, \mathrm{H}^{+} / 2 \mathrm{HS}^{-}\right)$was determined to be $0.69 \mathrm{~V}$ vs. NHE at $\mathrm{pH} 7$, whereas the reduction potential of $\mathrm{S}^{\cdot-}$ is estimated to be $0.92 \mathrm{~V}^{25}$ Therefore, the dimeric radical is a good reducing agent for a variety of organic molecules.

These above observations suggest the mechanism depicted in Fig. 3b: the $\mathrm{HS}^{*} / \mathrm{S}^{*-}$ radical couple generated by photolysis of $\mathrm{H}_{2} \mathrm{~S} / \mathrm{HS}^{-}$in aqueous environment abstracts a $\mathrm{H}$-atom from 1 to give the radical 4 . This species undergoes a $\beta-\mathrm{C}-\mathrm{O}$ scission and elimination of $\mathrm{H}_{2} \mathrm{O}$, with the shift of the radical center to give 5, which completes the $1^{\text {st }}$ catalytic cycle by reacting with $\mathrm{H}_{2} \mathrm{~S} / \mathrm{HS}^{-}$ regenerating $\mathrm{HS}^{*} / \mathrm{S}^{*}$. The so-formed cyclopentanone (2) is reduced to the radical anion 6 by the dimeric radical species $\mathrm{HSSH}^{\cdot-} / \mathrm{HSS}^{-2-}$. Subsequent protonation (7) and $\mathrm{H}$-atom abstraction from $\mathrm{H}_{2} \mathrm{~S} / \mathrm{HS}^{-}$affords the product 3 completing the $2^{\text {nd }}$ catalytic cycle. The reversible addition of $\mathrm{HS}^{*} / \mathrm{S}^{*}$ radical to $\mathrm{H}_{2} \mathrm{~S} / \mathrm{HS}^{-}$is the key step that plays a role in the efficacy of this conversion. Interplay of the various $\mathrm{p} K_{\mathrm{a}}$ values (known and still unknown) ensures that the dimeric radical species is present across the $\mathrm{pH}$ range (2-9) used.

The reduction $1 \rightarrow 2$ in aqueous solution has no precedent in the literature. The reaction of $\mathrm{HS}^{*} / \mathrm{S}^{-{ }^{-}}$radical with 1 is endothermic $(\sim 3 \mathrm{kcal} / \mathrm{mol})$, although polar effects should stabilize the transition state - based on $\mathrm{DH}\left[\mathrm{Me}_{2}(\mathrm{HO}) \mathrm{C}-\mathrm{H}\right] .{ }^{27}$ In the reaction of cis-1,2-cyclopentanediol, no trace of trans-isomer was observed, and vice versa for the reaction with trans-1,2-cyclopentanediol, suggesting that the reverse reaction $4 \rightarrow 1$ is much slower than water elimination. On the other hand, the reaction of radical 5 with $\mathrm{H}_{2} \mathrm{~S} / \mathrm{HS}^{-}$is thermoneutral - based on $\mathrm{DH}[\mathrm{MeC}(\mathrm{O}) \mathrm{CH}(-$ $\mathrm{H}) \mathrm{Me} .{ }^{26}$ The water elimination step $(\mathbf{4} \rightarrow 5)$ is a general feature in carbohydrate free-radical chemistry. ${ }^{8,28}$

Examining the data in Table 1, two features of the experiments at $\mathrm{pH} 9$ are notable: (i) cyclopentanone was undetectable, and (ii) there was less conversion of the starting material $(25 \%$ after 60 min of reaction time) compared to other $\mathrm{pHs}$. These data indicated the low availability of sulfhydryl radicals $\left(\mathrm{HS}^{{ }^{*}} / \mathrm{S}^{{ }^{-}}\right.$) at alkaline $\mathrm{pH}$, but the fast reduction of carbonyl moiety to 3 as described above. On the other hand, the reduction of the carbonyl moiety at $\mathrm{pH} 2$ is limited due to the very low concentration of the necessary radical species ( $\mathrm{HSSH}^{\cdot-} / \mathrm{HSS}^{\bullet-}$ ).

To determine the efficiency of the dimeric radical species $\left(\mathrm{HSSH}^{*}-\mathrm{HSS}^{-2-}\right.$ ) for one-electron transfer to a carbonyl group, the reduction of 2-hydroxy-cyclohexanone (8) at $\mathrm{pH} 9$ was examined. Photolysis (low-pressure $\mathrm{Hg}$ lamp, $5.5 \mathrm{~W}$ ) of $\mathrm{N}_{2}$-saturated aqueous solutions of $8(8.3 \mathrm{mM})$ containing $\mathrm{Na}_{2} \mathrm{~S} .9 \mathrm{H}_{2} \mathrm{O}(16.6$ $\mathrm{mM}$ ) was carried out for different times (up to $60 \mathrm{~min}$ ) at $\mathrm{pH} 9$. In all experiments, cyclohexanone (9) and cyclohexanol (10) were formed as the only products (eq 1). Fig. 4a shows representative 
GC analyses. Fig. 4b displays a graph with the disappearance of $8(\diamond)$ and the formation of $\mathbf{9}(\odot)$ and $\mathbf{1 0}(\Delta)$ as a function of the reaction time, showing clearly that the reaction $8 \rightarrow 10$ occurs stepwise. The loss of 8 was matched by the formation of 9 and 10 , with $2 \%, 21 \%$ and $77 \%$, respectively after $60 \mathrm{~min}$. The reaction also occurs at $\mathrm{pH} 7$, in a similar way, but much slower, e.g., after $20 \mathrm{~min}$, the conversion of 8 was $73 \%$ at $\mathrm{pH} 9$ and $37 \%$ at pH 7 (see Fig. S8-S9). Therefore, the overall reaction (1) proceeds via a dual catalytic cycle radical mechanism (see also Fig. S10).



Considering the efficiencies of the cyclopentanone (2) and cyclohexanone (9) reductions, the scope of the methodology for the reduction of carbonyl compounds to the corresponding alcohols was further explored. Thus, under identical experimental conditions, aldehydes 11 and 12 as well as ketones 13,14 and 15 all gave exclusively the corresponding alcohols with yield $\geq 90 \%$ (Fig. 5a,b, see also Fig. S11 and Fig. S12). The stereochemical outcome of the reduction process was studied using (-)-menthone (16) and (1R)-(+)-camphor (17). The reduction of 16 led to a 2:1 mixture of $(1 R, 2 S, 5 R)-(-)$-menthol and $(1 S, 2 S, 5 R)-(+)$-neomenthol in $83 \%$ yield, while the reduction of 17 gave a $7: 3$ mixture of (+)-borneol and isoborneol in close to quantitative yield (Fig. $5 \mathrm{c}$, see also Fig. S13). The method of reduction described is attractive because it occurs under mild conditions and employs inexpensive, easily removed reagents.

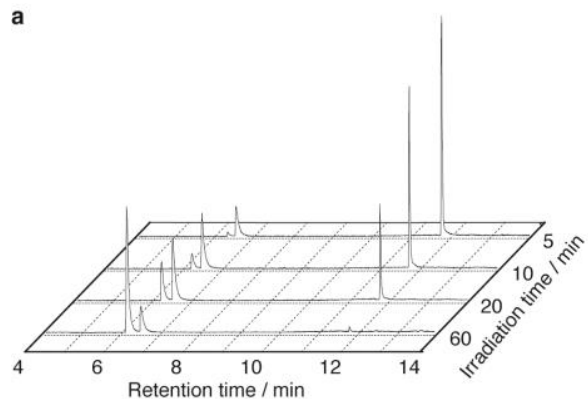

b

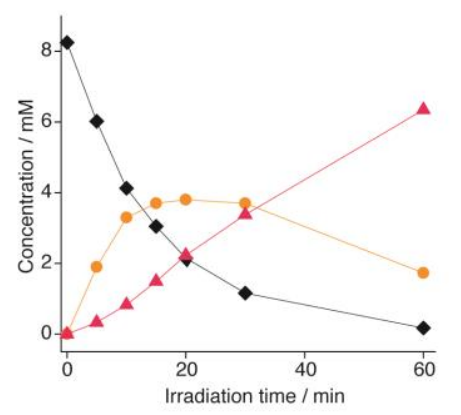

Figure 4. (a) GC analyses after photolysis of $\mathrm{N}_{2}$-saturated 2-hydroxycyclohexanone (8) aqueous solutions $(8.3 \mathrm{mM})$ containing $\mathrm{Na} 2 \mathrm{~S} .9 \mathrm{H} 2 \mathrm{O}(16.6 \mathrm{mM}), \mathrm{pH}$ adjusted to 9.0 , at $42 \pm 1{ }^{\circ} \mathrm{C}$ and different irradiation times. (b) Concentration of $8(\diamond), 9(\odot)$ and $10(\Delta)$ vs irradiation time at $\mathrm{pH} 9$ and at a constant temperature of $42^{\circ} \mathrm{C}$. a
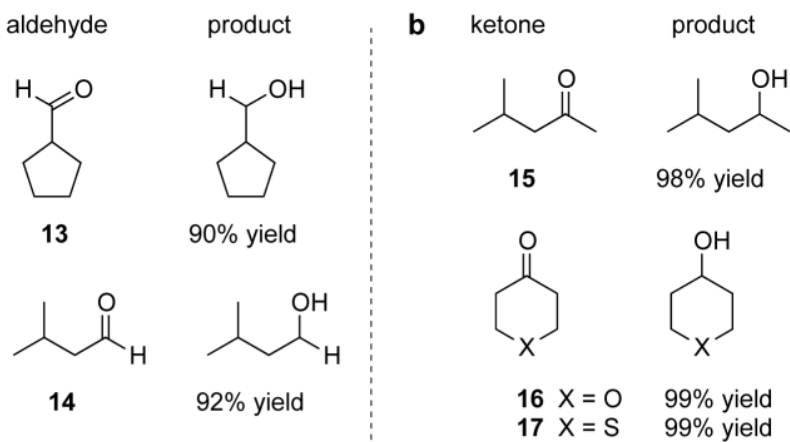

$16 \mathrm{X}=\mathrm{O} \quad 99 \%$ yield $17 X=S \quad 99 \%$ yield

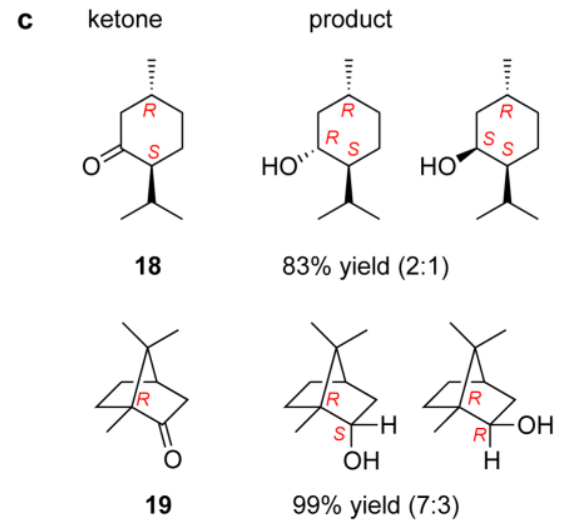

Figure 5. Reduction of aldehydes (a) and ketones $(\mathbf{b}, \mathbf{c})$ to the corresponding alcohols. $\mathrm{N}_{2}$-saturated aqueous solutions of carbonyl compound $(8.3 \mathrm{mM})$ containing $\mathrm{Na} 2 \mathrm{~S} .9 \mathrm{H} 2 \mathrm{O}(16.6 \mathrm{mM})$, pH adjusted to 9 at $42 \pm 1{ }^{\circ} \mathrm{C}$, were irradiated for $60 \mathrm{~min}$. Yields by GC analysis based on products formation (see SI for details).

In summary, we have described a highly efficient biomimetic method in aqueous environment to reduce 1,2-diols and carbonyl compounds to mono-ols with simple inexpensive reagents inspired by the biological transformation of ribonucleotides to deoxyribonucleotides. The method utilizes radicals $\left(\mathrm{HS}^{*} / \mathrm{S}^{--}\right.$and $\mathrm{HSSH}{ }^{-}-\mathrm{HSS}^{\bullet-}$ ) derived from hydrogen sulfide. Application of the methodology reported herein is in progress, and is being appropriately adapted for the reduction of ribose and other carbohydrates. The mechanism shown here can be also helpful for understanding other chemical transformations evoked in prebiotic life ${ }^{29,30}$, involving this simple molecule present in the mixture of gases on Earth and then substituted by cysteine and its disulfide in the actual biological environment.

\section{ASSOCIATED CONTENT}

Supporting Information

The Supporting Information is available free of charge on the ACS Publications website at DOI:

Experimental procedures and GC analyses of all reactions Figures S1 - S13 (PDF).

\section{AUTHOR INFORMATION}

\section{Corresponding Author}

* chrys@isof.cnr.it

\section{ORCID}

Chryssostomos Chatgilialoglu: 0000-0003-2626-2925

\section{Present Addresses}


‡Visiting Scientist. Permanent address: Universidad de Buenos Aires, Facultad de Farmacia y Bioquímica, Departamento de Química Orgánica, Junin 954, CP 1113, Buenos Aires, Argentina..

\section{Notes}

The authors declare no competing financial interest.

\section{ACKNOWLEDGMENT}

This work was supported by the EU COST Action CM1201 "Biomimetic Radical Chemistry." SBV acknowledges CONICET (Argentina) for partially funding the visit to ISOF-CNR.

\section{REFERENCES}

(1) McCombie, S. W.; Motherwell, W. B.; Tozer, M. J. Org. React. 2012, 77, 161-438.

(2) Chatgilialoglu, C.; Ferreri, C.; Landais, Y.; Timokhin, V. I. Chem. Rev. 2018, 118, in press. DOI: 10.1021/acs.chemrev.8b00109

(3) Eklund, H.; Uhlin, U.; Färnegårdh, M.; Logan, D. T.; Nordlund, P. Prog. Biophys. Mol. Biol. 2001, 77, 177-268.

(4) Minnihan, E. C.; Nocera, D. G.; Stubbe, J. Acc. Chem. Res. 2013, 46, 2524-2535.

(5) Licht, S.; Gerfen, G. J.; Stubbe, J. Science 1996, 271, 477-481.

(6) Greene, B. L.; Taguchi, A. T.; Stubbe, J.; Nocera, D. G. J. Am. Chem. Soc. 2017, 139, 16657-16665.

(7) Jin, J.; MacMillan D. W. C. Nature 2015, 525, 87-90.

(8) von Sonntag, C. Free-radical induced DNA damage and its repair: A chemical perspective; Springer-Verlag: Berlin, 2006.

(9) Speranza, G.; Buckel, W.; Golding B. T. J. Porphyrins Phthalocyanines 2004, 8, 290-300.

(10) Jiang, D.; Barata-Vallejo, S.; Golding, B. T.; Ferreri, C.; Chatgilialoglu, C. Org. Biomol. Chem. 2012, 10, 1102-1107.

(11) Steenken, S.; Davies, M. J.; Gilbert, B. C. J. Chem. Soc. Perkin Trans. 2. 1986, 1003-1010.

(12) Le Guenic, S.; Ceballos, C.; Len, C. Catal. Lett. 2015, 145, $1851-1855$.
(13) Möller, M.; Schröder, U. RSC Adv. 2013, 3, 22253-22260.

(14) Chatgilialoglu, C.; Ferreri, C.; Matyjaszewski, K. ChemPlusChem 2016, 81, 11-29.

(15) Fukuto, J. M.; Carrington, S.; Tantillo, D. J.; Harrison J. G.; Ignarro, L. J.; Freeman, B. A.; Chen, A.; Wink, D. A. Chem. Res. Toxicol. 2012, 25, 769-793.

(16) Szabo, C. Biochem. Pharmacol. 2018, 149, 5-19.

(17) Mishanina, T.V.; Libiad, M.; Banerjee, R. Nat. Chem. Biol. 2015, 11, 457-464.

(18) Stein, A.; Bailey, S.M. Redox Biol. 2013, 1, 32-39.

(19) Chatgilialoglu, C.; Ferreri, C.; Melchiorre, M.; Sansone, A.; Torreggiani, A. Chem. Rev. 2014, 114, 255-284.

(20) Lykakis, I. N.; Ferreri, C.; Chatgilialoglu, C. Angew. Chem. Int. Ed. 2007, 46, 1914-1916.

(21) Sutherland, J. D. Nat. Chem. Rev. 2017, 1, article no. 0012.

(22) Parker, E. T.; Cleaves, H. J.; Dworkin, J. P.; Glavin, D. P.; Callahan, M.; Aubrey, A.; Lazcano, A.; Bada, J. L. Proc. Natl. Acad. Sci. USA 2011, 108, 5526-5531.

(23) Dragičević, I.; Barić, D.; Kovačević, B.; Golding, B. T.; Smith, D. M. Chem. Eur. J. 2015, 21, 6132-6143.

(24) Hughes M. N.; Centelles, M. N.; Moore, K. P. Free Radic. Biol. Med. 2009, 47, 1346-1353.

(25) Das, T. N.; Huie, R. E.; Neta, P.; Padmaja, S. J. Phys. Chem. A 1999, 103, 5221-5226.

(26) Blanksby, S.; Ellison, G. B. Acc. Chem. Res. 2003, 36, 255-263.

(27) Zavistas A. A. Thermochemistry and hydrogen transfer kinetics. In Encyclopedia of Radical in Chemistry, Biology and Materials; Chatgilialoglu, C.; Studer, A., Eds.; Wiley: Chichester (UK), 2012; Vol. 1, Ch. 4, pp. 81-106.

(28) Ershov, B. G. Russ. Chem. Rev. 1998, 67, 315-334.

(29) Olson, K. R.; Straub, K. D. Physiology 2016, 31, 60-72.

(30) Bonfio, C.; Valer, L.; Scintilla, S.; Shah, S.; Evans, D. J.; Jin, L.; Szostak J. W.; Sasselov, D. E.; Sutherland, J. D.; Mansy S. S. Nat. Chem. 2017, 9, 1229-1234. 